International Journal of Engineering \& Technology, 7 [2.29] [2018] 716-718
International Journal of Engineering \& Technology
SPC
Website: www.sciencepubco.com/index.php/IJET
Research paper

\title{
Selecting the Affected Factors on Pavement Distress Problems Using Analytical Hierarchy Process [AHP]
}

\author{
Abdalrhman Milad ${ }^{1 *}$, Noor Ezlin Ahmed Basri², Mohammad K.Younes ${ }^{3}$, Hassan.M.Abdelsalam ${ }^{4}$, \\ Riza Atiq Abdullah Bin O.K Rahmat ${ }^{5}$ \\ 1,2,4,5 Department Of Civil And Structural Engineering, Faculty Of Engineering And Built Environment, \\ Universiti Kebangsaan Malaysia, 43600 UKM Bangi, Selangor DE, Malaysia \\ ${ }^{1,2}$ Sustainable Urban Transport Research Centre [SUTRA] \\ ${ }^{3}$ Civil Engineering Department Philadelphia University 19392 Amman, Jordan \\ *Corresponding Author E-Mail: Xyz_5001@Yahoo.Com.Sg
}

\begin{abstract}
This study describes the implementation of analytical hierarchy process [AHP] in pavement multi-criteria selection problem solving. The practice of expressing flexible pavement distress priority is widely accepted. However, an insistent demand exists for a technique that allows decision makers to determine their priorities, rational weights of the importance of pavement distress priority and the ranking of these factors. In this study, AHP is adopted in selecting the best level of distress in flexible pavements in Malaysia as an example of a tropical region. Knowledgeable and experienced experts in flexible pavement maintenance at jabatan kerja raya [JKR] and Kumpulan Ikram Sdn Bhd [IKRAM] were interviewed; as pairwise comparisons, their inputs were structured. Four criteria are set as follows: cracking, surface defects, surface deformations and patching and potholes. These criteria developed into a few other sub-criteria. Results show that cracking is the most significant factor [0.5500], followed by surface deformations [0.2300], patching and potholes [0.1600] and surface defects [0.0600]. Thus, cracking has the most significant distress among the four factors.
\end{abstract}

Keywords: Analytic hierarchy process; Flexible pavement; Pavement maintenance; Pavement deterioration

\section{Introduction}

Yearly, Malaysia substantially spends on the maintenance and rehabilitation of major and minor roads that exhibits distress, such as cracking and rutting. However, skilled individuals with specialised training and expertise in the area of pavement evaluation are lacking [1]. Investigation of pavement distress problems aims at implementing protective and rehabilitation measures to reduce the pavement deterioration process, thereby increasing the adequate life of asphalt pavements.

The performance of pavement maintenance is highly improved if promptly conducted in a pre-planned procedure. Practically, al pavement maintenance systems consist of priority models for flexible pavement maintenance activities. These models range from simple classifications to complex optimisation models. The quality of the prioritization process can directly influence the effectiveness of available resources that are mostly the initial judgment of a decision maker. A widely adopted practice of highway agencies is to make an exhaustive ranking of all the pavement maintenance projects or activities using experts' view and subsequently consume all funds to implement the top ranking activities [2].

Pavement maintenance preference is frequently represented by empirical mathematical indices [Fawcett, 2001; Broten, 1996; Barros, 1991], which constantly fail to demonstrate an obvious physical meaning; in addition, these references inaccurately and inefficiently convey the priority evaluation or goal of highway agencies and engineers.
Moreover, mapping the qualitative preferences to point estimates is constantly difficult, and a degree of doubt will be associated with some or all of the decisions. In an attempt to overcome the limitations mentioned above, this study explores the use of analytical hierarchy process [AHP] for the prioritization of flexible pavement distress activities. According to perceptive psychology, humans can only partially accommodate large quantities of information concerning problems. Therefore, based on a principle of pairwise comparison, AHP aims to determine the preferences of decision makers in terms of pavement distress and provides a useful tool in pavement maintenance prioritization. The suggested approaches ensure efficient decision making by representing and processing the actual data involved in the assessment [3].

\section{Methodology}

Pavement distress selection includes evaluations and assessments of several criteria and factors, which are unequal in terms of importance. In the proposed model, pavement distress is divided into three primary levels, namely, problem development, criteria analysis and selection and testing. Question development refers to defining the problem, objective, evaluation criteria, experts and their grouping. Measure analysis presents the extraction of expert knowledge and data analysis. Selection and testing refer to identifying the importance of pavement distress criteria using AHP, subsequently testing the consistency to assure that the initial observations are developed into new information. 


\subsection{Problem Development}

This step involves a literature review to construct the hierarchical structure of the pavement distress and determine the primary and sub-criteria that affect the pavement distress selection. Under each group of the main criteria, 4 main criteria and 13 sub-criteria are identified, which are distributed under each main criterion, as shown in Figure 1. Subsequently, three experts are selected and clustered into groups, namely, government [JKR] and nongovernment organisations [NGO, IKRAM]. A questionnaire is developed for comparison and determination of criteria and sub criteria; the experts are introduced to the problem and the process meaning and implications

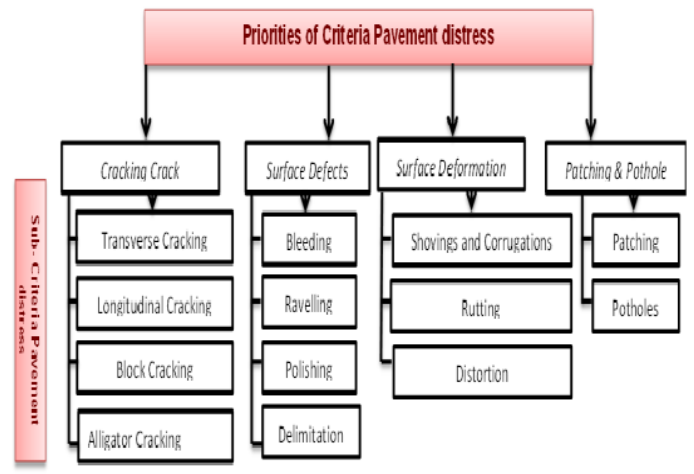

Fig. 1: Priorities of Criteria for Pavement distress

In AHP, the pairwise comparisons are considered the fundamental building blocks [4]. The comparisons are developed based on the preferences and experiences gained from the observation and continuous learning of the experts. Table1 presents the criterion ranking based on importance

Table 1: Definition of the scale of importance

\begin{tabular}{|c|l|l|}
\hline $\begin{array}{c}\text { Intensity of } \\
\text { importance }\end{array}$ & Definition & Explanation \\
\hline $\mathbf{9}$ & $\begin{array}{c}\text { Extremely } \\
\text { Important }\end{array}$ & $\begin{array}{l}\text { This activity is of the highest } \\
\text { possible order of confirmation }\end{array}$ \\
\hline $\mathbf{2}$ & $\begin{array}{c}\text { Strongly } \\
\text { important }\end{array}$ & $\begin{array}{l}\text { This activity is strongly favoured } \\
\text { [dominant] over other activities }\end{array}$ \\
\hline $\mathbf{5}$ & $\begin{array}{c}\text { Moderately } \\
\text { important }\end{array}$ & $\begin{array}{l}\text { This activity is moderately } \\
\text { favoured over other activities }\end{array}$ \\
\hline $\mathbf{3}$ & $\begin{array}{l}\text { Equal im- } \\
\text { portant }\end{array}$ & $\begin{array}{l}\text { This activity is slightly favoured } \\
\text { over other activities }\end{array}$ \\
\hline $\mathbf{2 , 4 , 6 , 8}$ & $\begin{array}{l}\text { This activity equally contributes to } \\
\text { the objective }\end{array}$ \\
\hline
\end{tabular}

Source: Fang \& Nan 2014

A score of 1 represents the indifference between two components, whereas a score of 9 denotes the overwhelming dominance of the component under consideration [row element in the matrix] over the comparison element [column component in the matrix; [5]. If the relative importance of element $i$ on element $j$ is represented by aij $=w i / w j$ in the pairwise comparison matrix, then, the pairwise comparison matrix A with $\mathrm{n}$ elements can be illustrated by Equation Matrix [1] [6]. Moreover, when scoring is conducted for a pairwise comparison, a reciprocal value is automatically assigned to the reverse comparison within the matrix. That is, if aij is a matrix value allocated to the comparison of the component to component $\mathrm{j}$, and then aji is equal to $1 /$ aij.

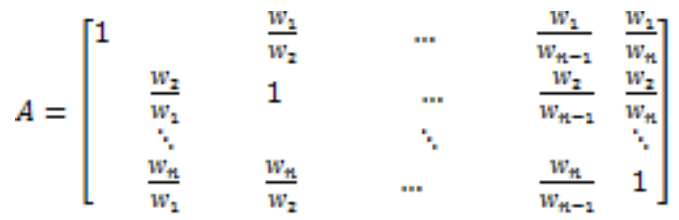

However, the used questionnaire in this study was developed after preliminary interviews with an expert. In the pilot phase, three experts on asphalt pavements were selected to respond to the questions, and their comments and suggestions were then considered.

\subsection{Priority Selection and Consistency Test}

The expert preferences, which contain the responses of government and NGO, are collected by the questioner and are subsequently applied in the AHP analysis to obtain the weights of each main criterion and sub-criterion. However, the consistency ratio is used to measure the preference consistency; such ratio generally represents the goodness of the judgment matrix and can be measured as follows:

$$
\begin{aligned}
& C R=\frac{C I}{R I} \\
& C I=\frac{\lambda-n}{n-1}
\end{aligned}
$$

Where CI, CR and RI are the consistency index, consistency ratio and random index, respectively. RI is determined using the tables available in the literature [7]. Finally, the integrated pavement distress-AHP analysis algorithm is summarised in Figure 2 and serves as a guideline for such decision-making problem.

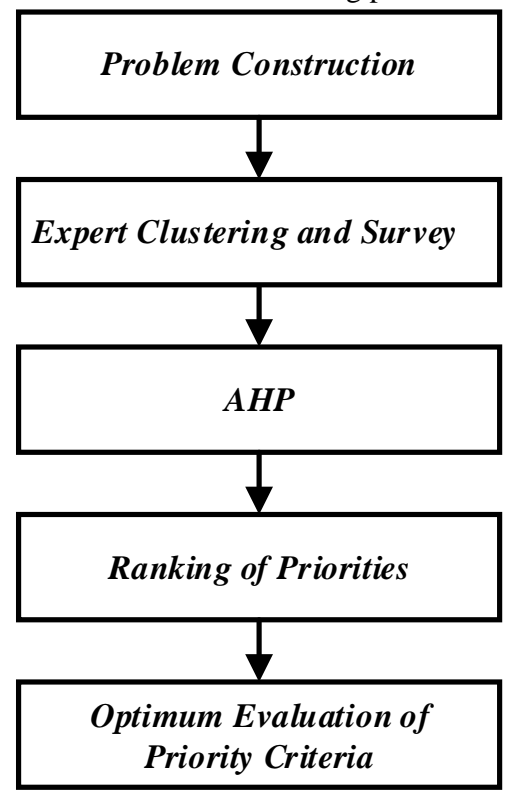

Fig. 2: Model AHP for Pavement Distress.

\section{Results and Discussion}

Table 2 lists the absolute priorities of the main group of criteria. The most dominant cause for road crack is the one with the highest rank [0.55], namely, cracking, followed by surface deformations [0.23] and patching and potholes [0.16]. Surface defect is the least frequent cause of road distress. Meanwhile, cracking in tropical regions affected by the excessive infiltration of precipitated water into pavement layers will cause several problems, including pumping soil particles through a crack water intrusion. In addition, progressive degradation of nearby road structures and reflection of shrinkage cracks are expected, especially in construction joints on bituminous surfaces. The main criteria play an essential role in determining the frequency of the sub-criteria because their weights significantly influence those of the sub-criteria and thus the overall process [8]. Moreover, the consistency ratio is computed to check the pairwise comparison. The resulting consistency ration is within the acceptable range [CR < 0.1]; the obtained consistency ratio [2.7\% and 4.7] indicates accuracy and coincides with the responses from the surveyed experts]. 


Table 2: Final priorities of the main criteria
\begin{tabular}{|l|l|}
\hline Main Criteria & Final Weight \\
\hline Cracking & 0.55 \\
\hline Surface Defects & 0.06 \\
\hline Surface Deformations & 0.23 \\
\hline Patching and Potholes & 0.16 \\
\hline
\end{tabular}

$\mathrm{CR}=2.7 \%$

Table 3 presents the final priorities of the most common pavement distresses. Overall, the highest rank is for alligator cracking [29\%], which is a common result of repeated overloading. The second frequency crack type in Malaysia is block cracking [15\%], which is caused by insufficient slab thickness, loss of sub-base support layers, asphalt shrinkage or fatigue cracking. The potholes, which are mainly the result of continued deterioration of another type of distress or poor surface mixtures, represent $10 \%$ of the pavement distress. The least frequent pavement distresses are bleeding, polishing, ravelling and delimitation with frequency ranks of $1 \%, 1 \%$, $2 \%$ and $2 \%$, respectively, as shown in Figure 3. The ranking indicates extremely low problems in the pavement distress, road preparation and application phases.

However, such results were reported in the study of [9]; the authors indicated that alligator cracking represents $24 \%$ of the total rural roads damaged in Batu Pahat District in Malaysia. Such distress is followed by patching [18\%], edge cracking [16\%] and transverse and longitudinal cracking [11\%]. However, the leading causes of pavement damage in Malaysia are related to vehicle overloading and climatic effects [10].

Table 3: Weight priorities of the overall sub-criteria

\begin{tabular}{|c|c|c|c|}
\hline Group & Criteria & $\begin{array}{l}\text { Priority } \\
\text { normalised } \\
\text { by group }\end{array}$ & $\begin{array}{l}\text { Final prior } \\
\text { ity [weight] }\end{array}$ \\
\hline \multirow{4}{*}{ 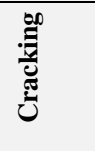 } & Transverse Cracking & 0.08 & 0.04 \\
\hline & Longitudinal Cracking & 0.11 & 0.06 \\
\hline & Block Cracking & 0.28 & 0.15 \\
\hline & Alligator Cracking & 0.53 & 0.29 \\
\hline \multirow{4}{*}{ 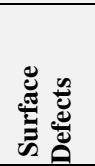 } & Bleeding & 0.15 & 0.01 \\
\hline & Ravelling & 0.33 & 0.02 \\
\hline & Polishing & 0.23 & 0.01 \\
\hline & Delimitation & 0.29 & 0.02 \\
\hline \multirow{3}{*}{ 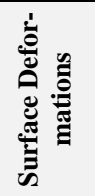 } & $\begin{array}{l}\text { Shovings and } \\
\text { Corrugations }\end{array}$ & 0.18 & 0.04 \\
\hline & Rutting & 0.56 & 0.13 \\
\hline & Distortion & 0.26 & 0.06 \\
\hline \multirow{2}{*}{ 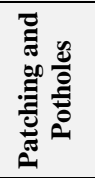 } & Patching & 0.37 & 0.06 \\
\hline & Potholes & 0.63 & 0.10 \\
\hline
\end{tabular}

$\mathrm{R}=4.7 \%$
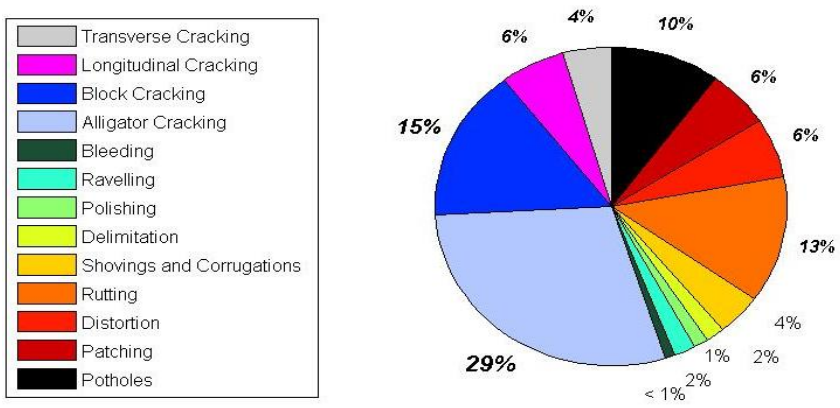

Fig. 3: Percentage weights of inconsistency for the sub-criteria.

\section{Conclusion}

The investigation in this study is based on the processing and analysis of collected data, and on the results of the entire ranking procedure, building and validation. The fundamental issue of the distress pavement process is defining the site evaluation criteria and building the dependencies among them. Thus, creating a hierarchical structure of the evaluation criteria and determining the expert clusters are crucial. The resulting ranks are logical and justified. The influencing factors of pavement distress are complicated to solve represent the core of mitigation measures. Furthermore, the resulting consistency indexes are within the acceptable limit $[\mathrm{CR}<0.1]$. However, the proposed procedure is the first attempt in combining statistical analysis with AHP to prioritise pavement distress criteria. Nevertheless, given that the proposed model involves the extraction of expert knowledge through AHP, it could serve as a reference point for future complex decisionmaking issues. The proposed model may be used as a guideline in solving actual complicated pavement problems, where adequate expert participation is essential. This model is designed to aid decision makers in justifying their assessments with minimum funds and expertise. However, further sensitivity analysis research is suggested.

\section{Acknowledgement:}

The authors would like to thank the Sustainable Urban Transport Research Centre [SUTRA], UKM for their assistance to provide all the facilities for this research.

\section{References}

[1] Milad A, Basri NEA, Borhan MN, Rahmat RAAO. A review of web based expert systems for flexible pavement maintenance Jurnal Teknologi. 2016;78[6]:139-47.

[2] Sharaf EA. Ranking versus simple optimization in setting pavement maintenance priorities: a case study from Egypt. Transportation Research Record. 1993[1397].

[3] Farhan J, Fwa T. Use of Fuzzy Analytic Hierarchy Process in Pavement Maintenance Planning.

[4] Meade LM, Presley A. R\&D project selection using the analytic network process. Engineering Management, IEEE Transactions on. 2002;49[1]:59-66.

[5] Saaty TL. Theory and applications of the analytic network process: decision making with benefits, opportunities, costs, and risks. Pittsburgh, USA: RWS publications; 2005. 47-8 p.

[6] Fang F, Nan W. Optimal Hierarchical Decision-Making for Heat Source Selection of District Heating Systems. Mathematical Problems in Engineering,. 2014;2014:1-10.

[7] Alonso JA, Lamata MT. Consistency in the analytic hierarchy process: a new approach. International journal of uncertainty, fuzziness and knowledgC-based systems. 2006;14[04]:445-59.

[8] Hülle J, Kaspar R, Möller K. Analytic network process-an overview of applications in research and practice. International Journal of Operational Research. 2013;16[2]:172-213.

[9] Nor AM, Masirin MM, Sanik ME. Site Investigation Of Road Drains For Rural Road On Batu Pahat Soft Clay [BPSC]. IOSR J Mech Civ Eng. 2014;11[2]:12-9.

[10] Endut IR, Holt GD, Shehu Z, Elma N. Factors influencing road infrastructure damage in Malaysia. 2014. 